\title{
Enact, Discard, Transform: An Impact Agenda
}

\author{
Jennifer E. McGarry \\ University of Connecticut
}

\begin{abstract}
In her 2019 Earle F. Zeigler address, Jennifer McGarry drew on the 2017 Academy of Management Report "Measuring and Achieving Scholarly Impact" to examine how the field of sport management and the North American Society for Sport Management operationalize impact. She pointed to a broader, more inclusive, and critical examination of impact. McGarry highlighted impact on practice and impact through being explicit, particularly about the ways gender and race affect what we deem to have impact. Finally, she spoke to impact through individual and collective action, such as educating students, scholarship, and policy and advocacy. She provided examples of where we could disrupt the structures that work to maintain the status quo in terms of impact - the in-groups and the out-groups, the metrics and evaluations. She also gave examples of impact that have happened, that are happening, and that can happen even more.
\end{abstract}

Keywords: feminism, interorganizational relationships, leadership, organizational culture, race

The Zeigler Award is the most prestigious award given by the North American Society for Sport Management (NASSM) and may only be bestowed on an individual once over their career. So, good news-you only have to listen to me once. This year, I have the opportunity to pay a special tribute to Earle Zeigler, who left us in September at the age of 99. I am honored to be presented with the award that bears his name. Dr Zeigler's career spanned more than 70 years and five institutions, including a position at the University of Connecticut—one we share in common. He taught and later served as Dean at Western Ontario until he retired in 1989. He was a multisport athlete at Yale in the late 1930s and coached football, swimming, and wrestling at Western while serving as department head. I also want to point out the impact Dr Zeigler had on the field. He served as an advisor to over 100 graduate students during his career, and NASSM's history is full of those he mentored and/or served with as a colleague, as well. Earle Zeigler's "coaching tree" is impressive. I asked Dr Packinathan Chelladurai (Chella) to reflect on Dr Zeigler's mentorship, and it made me realize that almost every one of us have been impacted by Earle Zeigler. It was Dr Zeigler who hired Chella at Western to teach the first undergraduate sport management course, and then suggested that he write the text book for the class, which he did. Those of you who have used any of Chella's textbooks and articles have not only him to thank, but also Dr Zeigler, as well. His legacy lives in the people he influenced and continues to influence.

The nature of this event has changed in recent years from the concluding event on the last night to a morning keynote on the first full day of the conference. This means that I can experience the conference not like someone with all their exams at the end of finals week, constantly worried whether they have prepared enough while simultaneously wondering if they have overprepared. I always hated that. So, I appreciate the change, in particular, this year. In about 40 minutes, I will be the most relaxed NASSM

The author is with the University of Connecticut, Storrs, CT, USA. McGarry (jennifer.mcgarry@uconn.edu) is corresponding author.

Inspired by Vernice Thandi Sulé's 2014 article: Enact, discard, and transform: A critical race feminist perspective on professional socialization among tenured Black female faculty. attendee in the place. Yes, that is the over-under for those taking bets. I aim to provide my observations of our field from the only vantage point I can, mine. However, my vantage point has been influenced by many people and experiences. I have been impacted. Yes, again, for those of you who like to add competition (Shilbury, 2012) into everything, including Zeigler addresses, the word is impact. I have given thought to what it means to have impact. I hope to leave you with some thoughts on that, as well.

IMPACT - There have been 28 Zeigler award winners in total, after Earle as the inaugural winner. Donna Pastore, Janet Fink, Mary Hums, Alison Doherty, Lucie Thibault, Karen Danylchuk, Sue Inglis, Wendy Frisby, Jackie Cuneen, Joy DeSensi, Chris Green, Brenda Pitts, and Janet Parks make 13 women. I am the 14th. In a male-dominated field, that is something to take note of. Can those women who are here please show us where you arestand if you are able, wave a hand? I want to acknowledge their impact. Please stay where we can see you.

I recently listened to The Year of Yes by television producer Rhimes (2015). Although many aspects of her advice resonated with me, one point stood out. Rhimes reflected on receiving an award for excellence among women in entertainment. That night, she surveyed the room. "Not a single woman . . . could handle being told, "You're awesome." She herself could not handle being told you are awesome. The women looked down, smiled uncomfortably, fidgeted in their seats while being named as past winners. Rhimes said to herself, "what in the hell is wrong with us?" To each of you who have inspired me and others, I am going to share the rest of her message:

You are not lucky. You know what you are? Smart, talented, you take advantage of the opportunities that come your way and you work really, really hard. Don't ever call yourself lucky. Call yourself a badass.

And in case you need a definition of what that means:

Badassery: (noun) the practice of knowing one's own accomplishments and gifts, accepting one's own accomplishments and gifts and celebrating one's own accomplishments and gifts (Rhimes, 2015, p. 177). 
Thank you all for being the badasses that you are. I am honored to be listed among you. And to every other badass woman out there, keep doing what you do and take credit for it. If you ever need any support or inspiration to sustain doing what you do and taking credit for it-these women and I are here for you.

In particular, I would like to recognize Donna Pastore. I thank you for what you saw in me when I came to meet you, unsure of my next steps as a coach and an administrator fed up with the inequities of college athletics. I will never forget your story of frustration over similar issues as a college softball coach and how that led to the fateful game when you launched a bat bag onto the field, spraying bats everywhere. That was when you decided your days of coaching were numbered and you poured yourself into a $\mathrm{PhD}$ program to find other vehicles for change. Working with you through my doctoral program and beyond has helped me learn how to effectively redirect the desire to literally throw bats when I am fed up, to instead, figuratively throw bats with my teaching, research, engagement, and leadership.

I attended my first Zeigler address in 1998. Or, as my kids would say when they are reminding me of my age, way back in the 1900s. Dennis Howard, my finance professor at the time, appreciated that the award was a big deal, but it was my first NASSM, and this guy was my professor. And while I was certainly in awe of his abilities in that regard, as anyone who could teach me stadium financing certainly deserves an award, it did not completely sink in what this was all about. Over the years, however, I have grown to understand the significance of the award. It really is a big deal to be recognized by one's peers for work across a career. I certainly reacted much the way Dr. Howard did as he relayed in his Zeigler address-Me? There are [many] so much more deserving than me - then I remembered Shonda Rimes telling me to embrace my badassery. And I moved on to what Dr. Howard shared next. Wait, am I that old that I would be considered for the Zeigler? Yep. And after a few days, finally, I arrived at "hold on, I have to give this talk" to a great, big room full of people (Howard, 1999, p. 78). For those of you who know me, you know that I have no problem talking, telling stories to make my points, and questioning. But I tend to wade in, not dive in. I build relationships, lead people to consensus. So how to address a room of people in a diversity of roles and positions in colleges, universities, and industries, representing so many different subfields within, and approaches to, sport management. This is a unique challenge.

Or, it is an opportunity. When my all-time favorite baseball player, Ryne Sandberg, addressed his peers, he used the opportunity to talk about how he played the game and what it meant to him. He knew by doing so he was going to be critical of how others played the game. And that was not his persona, but he had the opportunity to tell it like he saw it, and he did. Now, please, please understand I am not saying today is analogous to late summer in Cooperstown, and I can only dream that I ever had the chance to play second base at Wrigley. I am just saying that I have been asked to talk about sport management from my perspective. My perspective is critical. Here goes.

\section{Impact}

Haley and her colleagues, in a report from the Academy of Management (AOM), defined scholarly impact as an "auditable or recordable occasion of influence" arising out of research. This is tangible, quantitative, and some might even say, objective. However, making meaning of academic impact in a "pluralistic" way or "in ways other than peer-reviewed publications becomes much more difficult and requires significant investments of time and effort" (pp. 2-3). Haley, Page, Pitsis, Rivas, and Yu (2017) engaged in an initial grounded, qualitative study in order to frame scholarly impact before considering a larger, quantitative study of the AOM membership as they pointed out, "simply counting rarely provides useful information" (p. 4). Rather, they elected to "participate with real people" (p. 18) or 20 impactful members of AOM. They engaged their colleagues about the "meaning and sensemaking of scholarly impact and for whom" (p. 2).

Using Haley's work as a model, I have reached out to several past Zeigler award winners and also to scholars whose perspectives I consider to have an influence on our field. I have asked them to comment on segments of the AOM findings, as well as their own work. Thank you to Donna Pastore, Alison Doherty, Lucie Thibault, Janet Fink, John Singer, Wendy Frisby, George Cunningham, Mary Hums, Akilah Carter-Francique, Nef Walker (my former Diversity Committee cochair), and Rhema Fuller and Kristy McCray (current Diversity Committee cochairs). And thanks to Rob Ammon and Orland Hoeber for digging a little deeper to locate all of the NASSM membership data.

As with what Haley found, rigor, academic quality, and academic productivity all continue to play a role in conceptualizing impact in sport management; however, when taken alone, these factors are insufficient. Our colleagues and the AOM scholars agreed that, while publishing in top-tier journals is certainly a marker of impact, our "broader role and . . . mission" (Haley et al., 2017, p. 3) extends further. So today, I am asking you to consider how we have, and I contend should, conceptualize impact in sport management.

\section{Impact on Practice}

In 1991, Janet Parks stood in the spot I occupy this morning and spoke to the nature of sport management scholarship as both theoretical and applied. She quoted Boyer and stated that our scholarship should reflect Boyer's discovery, integration, teaching, and application. Just as our students have not realized the depths of their knowledge until they apply classroom learning in the "real world," our scholarship should reflect Boyer's constructs and bridge the real or mythical gap between research and practice (Parks, 1992). Jim Weese, in his 1994 Zeigler address, asked us to consider that, if we are not serving practitioners, then we are not serving our field (Weese, 1995). He cited his conversation with management expert Henry Mintzberg. Mintzberg entrusted two colleagues to provide him with real, and critical, feedback on all of his work. Mintzberg's Bill and Barbara could easily be Geno (Auriemma) and CD (Chris Dailey), reminding us that our academicspeak-filled, highly theoretical study on positive workplace culture was quite obvious to them after years of building national championship teams. They would then ask us if we were conducting our research as "an end in itself" (Weese, 1995, p. 238 from Mintzberg, 1982, p. 243) and to engage only ourselves, sport management scholars, in the discussion. Or, were we thinking of sport managersmany of whom are graduates of our programs? Dr Ziegler, in his 1987 address to the NASSM membership, spoke to how we should be considering both theory and application as he elaborated on the then NASSM mission statement, stating that this organization exists to "serve the evolving profession as a whole-not any specific individual, group, or university" (Zeigler, 1987, p. 5).

Cuneen and Parks (1997) responded to Weese's Zeigler point by sharing that NASSM, and the Journal of Sport Management (JSM) in particular, were serving sport managers as part of the larger umbrella of sport management education. Practitioners 
should not be a protected class, they said, or a specific group, like the mission statement said, but rather members of the profession as a whole. They spoke of NASSM and JSM being "conceived and implemented by a diverse group of scholar-educators with the clearly defined purpose of promoting, stimulating, and encouraging study, research, scholarly writing, and professional development" (Cuneen \& Parks, 1997, p. 126). While I am thankful that women like Parks and Joy DeSensi were founders, I know that not everyone here can see themselves in this "diverse group of scholar educators" (Cuneen \& Parks, 1997, p. 126).

At this conference, a group of our colleagues are holding a symposium. "Why Are All the Black Scholars Going to NASSS? A Reflective Dialogue on the Under-Representation of Black Scholars at the NASSM Conference." As John Singer, one of the presenters, shared with me, it is important to use your platform in a constructive and productive way. Wendy Frisby related a story of how she too was unsure of whether sport management and NASSM were where she belonged, given her critical approach. In fact, if it were not for Trevor Slack reaching out, her approach would not have helped to shape JSM as an associate editor and editor for 8 years. As a result, we could possibly not have had papers like Shaw and Hoeber's (2003). I am getting all my swears in this talk, aren't I? Dr Frisby talked about how important that paper was and how important that title was. It was explicitly naming a critical issue in sport management. So, when we say that everyone is "welcome to join NASSM, attend the annual conference, and stand for election to the Executive Council" (Cuneen \& Parks, 1997, p. 129), is this in theory or in practice? Or both? Does everyone feel welcome to join, to attend, to serve?

Critical management studies outline that, as both technology and bureaucracy have expanded, individuals are encouraged, even rewarded, for assimilating. Those who control the means of production, yes, even scholarly production, control the production itself, and those who do not are subject to it. This is Marx as relayed through Neuman (2003). If we do not acknowledge the individuality of our membership - our most salient identities - then power relations are not challenged (Alvesson, 2008; Caproni \& Arias, 1997; Shaw, Wolfe, \& Frisby, 2011). I want to thank those who are presenting tomorrow-Jaqueline McDowell, John Singer, Akilah Carter-Francique, Charles Crowley, and Nef Walker-and Trevor Slack, Wendy Frisby, Sally Shaw, and Larena Hoeber, for challenging power relations in theory and in practice. That is impact.

\section{Impact Through Being Explicit}

In the 2015 Zeigler address, Janet Fink pointed to multiple examples of sexism-how sexism remains relatively "uncontested in sport." It "is commonly overt yet simultaneously unnoticed. It hides in plain sight. It is so entwined in the fabric of sport that most do not even discern it" (Fink, 2016, p. 1). In speaking with Dr Fink recently, she shared that, in the 4 years since her Zeigler address, only one manuscript has been published in a sport-related journal explicitly naming sexism. We do not name it. Appreciation to Liz Taylor, Allison Smith, Natalie Welch, and Rob Hardin for their paper on female faculty experiences of sexual harassment and sexism in the Women in Sport and Physical Activity Journal (Taylor, Smith, Welch, \& Hardin, 2018).

If we cannot be explicit about the experiences of those who participate in, manage, and teach sport in our scholarship, then how can we make those experiences better? Fink quoted some of her earlier work in her Zeigler stating that
Sexism in sport is not tidy, it is a downright messy matter. The ideals of meritocracy and fair play embedded in sport make it difficult for people to believe that it provides advantages for some groups over others ... (Fink, 2008 in Fink, 2016, p. 4).

Shaw and Frisby (2006) stated that we have to critique practices at the structural level that reflects sociocultural, embedded beliefsmany of which are entirely implicit - that allow us to think we are treating everyone the same. We have to be explicit about who we are. We have to be explicit about how that impacts our experiences, and we have to be explicit about how it makes us feel.

The NASSM is an overwhelmingly White, U.S.-based, and male organization $(32 \%)$. White women from the United States are the next (21\%), followed by Asian males from the United States (7\%; North American Society for Sport Management, 2019); who we are impacts the experiences of our members and how they feel. In 2016, at the request of the Diversity Committee and Executive Council, a survey was developed to assess the NASSM climate. Nef Walker and Nicole Melton, as part of the Diversity Committee, developed the survey, and George Cunningham, as part of the Executive Council, oversaw the analysis and reporting of the results (North American Society for Sport Management, 2016b). Members were asked to respond, and 117 did, to items measuring the diversity climate of the organization, benefits from membership, and general satisfaction with NASSM. Overall, the study showed that the strongest level of agreement was with the notion that NASSM leaders were committed to diversity. Respondents in total were less supportive of the notion that new people could easily become involved in NASSM. Women were less likely to agree that NASSM publicized diversity principles, and those from underrepresented racial/ethnic groups were less likely to agree that NASSM leaders valued diversity. Sexual minorities were less likely to agree that NASSM (a) had open communications regarding diversity and inclusion, (b) publicized diversity and inclusion principles, (c) respected the voices of people like them, and (d) maintained a diversity-friendly environment. In total, though, the participants expressed their satisfaction with NASSM.

We could easily have walked away from these results and said that, although some individuals and small groups felt differently about NASSM, the majority were satisfied. But we did not. As part of the larger NASSM Strategic Plan process, we conducted a qualitative follow-up in 2018, aimed at gaining a deeper understanding of members' experiences. A working group-Joyce Olushola, Michael Odio, and Kyle Rich-was asked to examine the NASSM strategic goals focused on understanding and serving the perspectives of underrepresented and underserved stakeholders. Fifty-six members responded to a 10-item, open-ended survey. When asked, members indicated that many aspects of identity politics, in addition to the type of institution and subdiscipline, contributed to being undervalued and not represented. The most frequent responses were related to race, gender, ability, sexual orientation, geographic location, and professional status. Students and junior faculty indicated the most negative impacts as a result of professional status. In addition, NASSM members who worked in primarily teaching roles and/or at teaching institutions, as well as various subdisciplines, (e.g., law, economics, and analytics), responded that their experiences were not centered by the organization (North American Society for Sport Management, 2018).

The report highlighted three areas for us, NASSM, to consider. The first area was removing barriers and providing opportunities. Members indicated that diverse groups within NASSM should be 
recognized as valuable to the organization. I will interject that one important step is to continue to support the spaces that exist for diverse groups to contribute and/or build relationships. Some notable examples include the international reception, student mentoring initiative, Diversity Breakfast, and Women in NASSM, and then increasing such spaces. As an example, a former UConn student, Xaimara Coss, has worked for the National Basketball Association (NBA) for almost 10 years. She is the chair of CONEXIÓN ÉNE-BÉ-A, the Latino Employee Resource Team. Teams like this did not exist before the transition in league leadership. Barriers have been removed and opportunities added for Xai and her coworkers. The NBA inclusive culture site states "Our goal is to move from a diversity reflex to an inclusion instinct. The NBA strives to cultivate a workplace in which everyone feels welcomed and empowered to bring their whole selves to work" (National Basketball Association, 2019). That is impact.

Next, "diversifying" the conference/program. NASSM members also indicated that barriers to full participation must be removed - particularly the cost of membership and the conference and the types of sessions at the conference. I should say that sessions like the teaching and learning fair are a noted addition to the conference in more recent years, and the Diversity Committee's presentation list has helped members navigate the conference. Thanks also to Natalie Smith and Kerri Bodin for their NASSM blog on advice for first-time conference attendees. However, when people have many conferences to choose from, and only so much, if any, financial support from their institutions, why pick NASSM? I'd point to my educational leadership colleagues and how their organization, University Council for Educational Administration, supports the involvement of graduate students, particularly those from underrepresented groups, with identified sessions, workshops, mentoring, and funding for membership and conference attendance.

The NASSM members also encouraged a more integrated approach to diversity and inclusion, including active recruiting for committee roles, and more quality, inclusive experiences for members on those committees. As Pastore shared in her 2002 Zeigler, from Kram's (1988) mentoring framework, inclusive experiences can be characterized by peer relationships that provide confirmation-or sharing perceptions, values, beliefs, and finding commonality-emotional support, personal feedback, and friendship (Pastore, 2003). Members also acknowledged that in- and out-groups exist within NASSM. These "continually reproduce existing personal and professional networks which are difficult to breach and antithetical to the values of a diverse and inclusive organization" (North American Society for Sport Management, 2018). Some suggestions included enacting a commitment to inclusive practices throughout the coordination of the conference and the organization more broadly. In particular, members urged the development and articulation of a position statement.

And finally, NASSM members suggested rethinking leadership, relationships, and organizational culture. Members indicated that, in order to move NASSM toward a diverse and inclusive organization, a culture shift has to happen. This would need to entail more than demographic surveys and could not be relegated to the Diversity Committee. We need to examine the relationship between the Executive Council and that committee, the makeup of editorial boards and abstract reviewers, and articulate what diversity looks like in this context and how a diversity of perspectives could be better achieved. We need to share the results of NASSM activities, like these two reports I am citing, which seek to improve the experiences of historically undervalued and underrepresented members. Our colleagues George Cunningham and John Singer, in their report on NCAA member institutions (National Collegiate Athletic Association, 2009), summarized one aspect of their findings by stating

Human communication is one of the most basic and fundamental functions of individuals within an organization ... leadership plays a vital role in setting the tone for the discourse on issues of diversity and inclusion . . . this openness is necessary if there is a genuine interest in creating and sustaining a culture in which diversity is valued (National Collegiate Athletic Association, 2009, p. 18.)

We need to be explicit about where we need to improve, what we are committed to doing to improve, and then the results of our actions. That would have impact.

\section{Preparing Critical Sport Managers and Future Educators and Scholars}

So far, what I have talked about might seem like too much for anyone to tackle and also hard to imagine any organization tackling. However, impact through both individual and collective action (Cunningham, 2014; Doherty, 2013; Mahony, 2008) is possible. One way that many of us have almost daily individual impact is with our students. We play integral roles in their socialization into sport management. As Shaw et al. (2011) outlined, we can teach our students to be voices that challenge. In sport, and in our institutions, the overwhelming majority of which are White and reflective of patriarchal structures, socialization occurs within "a legacy of race and gender exclusion" (Sulé, 2014, p. 432). We can have impact on this legacy by adopting a critical management approach. By intentionally-explicitlyacknowledging individual, organizational, and sociocultural (Dixon \& Bruening, 2007) antecedents and outcomes, we challenge our students to see "management as a social construction ... influenced by power and ideologies" (Neuman, 2003, p. 3).

As teachers, we can facilitate our students critically examining "decision-making hierarchies, evaluation systems, and dominant beliefs that determine rules of behavior" (Sulé, 2014, p. 432). When we expose and interrogate management practices grounded in stereotypes, we inform and encourage our students to lead in ways that produce more equitable outcomes-outcomes that are not antithetical to the bottom line and can, in fact, improve it (Alvesson, 2008; Meyerson \& Kolb, 2000; Shaw et al., 2011). This past semester my colleague, Danielle DeRosa, and I taught a Career Development course to all of our undergraduate students. We devoted a significant portion of the class to examining how social identities shape career paths, how organizations consciously and unconsciously demonstrate their values, and leading with a critical management lens. During our last class, we asked our students to reflect. They said,

We are seeing sports from a different perspective. Topics are very relevant to the real world and societal issues are connected to each class.

This class takes a very critical lens towards sport which I appreciate as I feel it allows us to discuss challenging topics.

We are learning about inequalities in the professional workplace. We have a deeper understanding about what diversity and inclusion means because we think about it on a day to day basis. 
And then the students spoke to the program as a whole:

The greatest impact has come in how we view people. Prior to being admitted to this program some of us did not really consider outside circumstances and influences on people's life choices and positions ... . [this program] has shown that there are circumstances outside of individuals' control, and we have to understand the influence of these circumstances.

As individual educators, we have come together to build a program that explicitly addresses inequity and impacts our students" "potential for resistance and change" within power structures (Shaw et al., 2011, p. 2). Our classrooms are high-leverage spaces. I encourage you to approach yours as spaces to disrupt, not reinforce, norms. Consider how management could look differently (Alvesson \& Deetz, 2000). You know, throw a figurative bat or two across the field.

As I read through the conference program to find current and former UConn students, the topics were not lost on me: critical examinations; Rachel Madsen, gender and negotiation; Jon Welty Peachey, sport for development; Rhema Fuller, the role of teaching institutions; Josh Lupinek, buying beer at NFL games-not sure what happened there, but there is one in every crowd; Mike Mudrick, social identity in sport talk radio; Jaime Ryan DeLuca, applied approaches in the teaching and learning fair; and, my current students Kolin Ebron and Jun Cho, mapping life skill development with youth sport program alumni, and Nneka Arinze, peer relationships among Black and Latina girls in sport-based youth development. Through our teaching, we can have impact. We are preparing future sport managers who are examining identity politics and their impact on organizations and future scholar educators ready to challenge the status quo.

\section{Impact Through Scholarship}

The goal of research can be to empower. If our purpose is only to study_and not to change (Neuman, 2003)—or, to Dr Fink's point, only to admire sexism but not to do away with it, if it is not to pull back W.E.B. DuBois' metaphorical veil, then ultimately, what is our impact? (DuBois, 1903). As Haley et al. (2017) shared, the majority of AOM eminent scholars communicated that faculty publish "in a limited number of journals with little attention to influence or true impact" (p. 10). In our field, we can point to that limited number of journals, and we can point to the mainstream topics and approaches addressed in them. We can also point to the critical issues and approaches and locate them, historically and primarily "in special issues ... dedicated to 'difference,' ..." (Shaw et al., 2011, p. 1). In Ketra Armstrong's introduction to JSM's special issue on race and ethnicity, she wrote:

It is my hope . . . that the scholarship featured in this Special Issue encourages Sport Management scholars at the personal and professional levels to be more willing to address race and ethnicity openly, directly, and cautiously . . . (Armstrong, 2011, p. 104)

How can the impact of that special issue be felt in the ways in which we "understand the nuances of managing sport ... [and] navigate our epistemological . . . approaches" (Armstrong, 2011, p. 104) to create impact with our scholarship beyond special issues? Broader impact. The National Science Foundation (NSF) requires broader impacts statements on all of its grant applications. NSF desires intellectual merit and broader impacts that have "the potential to not only advance knowledge, but benefit society"
(National Science Foundation, 2019). Look at the increase of scholarship on sport for development in our top-tiered journals (e.g., Schulenkorf, Sherry, \& Rowe, 2016; Spaaij, Oxford, \& Jeanes, 2016; Svensson \& Levine, 2017). Here is a key example of how the "process of inquiry [can reach] beyond [the] surface" to critically examine structures in a way that can lead to change through partnerships between community leaders and scholars (Neuman, 2003, p. 81). In order for our scholarship to have such broader impacts, we have to acknowledge that no neutral stance exists. In adopting a critical social frame where the goal of research is to empower, we acknowledge that "being objective is not being value free" (Neuman, 2003, p. 116). We then can challenge the belief that our research "must be protected from politics" and instead can be a tool for "emancipatory social change" (Harding, 1986, p. 162).

Our scholarly impact should extend beyond traditional means of evaluation too. The AOM scholars shared that "the present system of faculty evaluation and ... rankings have led to an overreliance on techniques, methodologies, and what journal editors may find acceptable." They continue even more critically, stating that the present system serves to benefit "career-aspiring ... academics with a corresponding under-reliance on ideas, community . . . and . . . limited societal impact" (Haley et al., 2017, p. 9). These scholars call for us to challenge our taken-for-granted assumptions on measuring impact and the resultant evaluation systems. When responses were summed, the majority of the AOM's members $(60 \%)$ indicated that rankings and lists probably did not, definitely did not, or might or might not reflect scholarly impact. They stated:

the incentive systems are not aligned [with engaging in impactful scholarship].

. . . we tend not to research real-life problems, do not work enough with government, and do not publish in vehicles that influence business ... policy and practice ... We do have vehicles that reach managers, but these do not count for much ... (p. 21)

Our evaluation systems are imperiling external impact and incentivizing the wrong behaviors. It is not an either-or proposition. It is yes, and ...

My colleague Justin Evanovich is a scholar activist. He serves as the Managing Director of Husky Sport (www.huskysport.uconn. edu). Every week he applies his research to practice as he challenges the students in his Sport Based Youth Development course. See the Sport Management Education Journal and Sport Management Review. He asks students to critically examine structures that historically deny opportunities (e.g., sport, education, health) to youths based on their ethnicities and socioeconomic status. Then he manages the campus-community partnership that connects the UConn and Hartford communities to collectively work to dismantle these structures because, to him, it is not enough only to discuss and research the issues.

My colleague Joseph Cooper is a scholar activist. His research on the holistic development of college students is at the nexus of sport, education, race, and culture. His work can be found in Sport Management Review, the Sociology of Sport Journal, and Whiteness in Education. Dr. Cooper founded Collective Uplift and empowers students across racial and ethnic backgrounds at UConn within and beyond their roles as college athletes every day. He is publishing his work outside the academy too. Take a look at his piece in The Conversation entitled "Dangerous Stereotypes Stalk Black College Athletes" (Cooper, 2019). 
My colleague Laura Burton is also a scholar activist. She is a NASSM Research Fellow and published in journals such as Quest and the Harvard Education Review on gender in leadership. What you might not know is that she has served as an expert witness or written an expert report in four cases of wrongful termination of female collegiate sport coaches, including the high profile $\$ 1.43 \mathrm{M}$ outcome for former University of Iowa athletic administrator Jane Meyer on all claims - gender and sexual orientation discrimination, retaliation and whistle blower violations, and unequal pay (Emmert, 2017). These two are having impact. They are committed to what they do, and we have developed a culture in our department that not only supports the work they are doing, but also celebrates it. As an aside here, I am the department head. Not coaching three sports, just being the department head. Seriously, though, one way to make change is to lead it yourself. A plug for those of you thinking about how you can have impact. One hundred twentyseven women in the U.S. Congress would tell you the same thing.

As leaders, we can change the reward structure and, as a result, change our professional socialization. We can leave it at the individual level, as Holosko and colleagues in social work have highlighted. The "wrong behaviors" can continue to be incentivized and the Black, female (you insert the identities) academics-will "just have to learn to live with [it]" (Holosko, Barner, \& Allen, 2016, p. 727). Or we can work to change the system. We can continue to use citations and indexes, or we can recognize, like the field of psychology has, that these "reflect systematic ... differences" and instead use "caution when relying on metric[s] to promote and reward" scholars (Geraci, Balsis, \& Busch, 2015, p. 2023).

\section{Impact for Policy and Advocacy}

I am going to bring it back to Boyer here. My colleagues Rachel Madsen, Justin Evanovich, Rhema Fuller, and I also wrote, using Boyer's framework,

. . . Boyer (1990) examined the American professoriate identifying the increasing emphasis on research, grants, and publications as antithetical to the reasons many are called to higher education, "a love for teaching and for service-even for making the world a better place" (Boyer, 1990, p. xii).

We went on in what now I realize has the uncanny feel of a Zeigler address. Who would have known?

The leaders in the field of sport management have been calling ... [our] professoriate to engage in the world for many years. From Frisby (2005) challenging us to examine critically the structures and the cultures of sport to Chalip (2006) urging us to identify areas for change in sport to Inglis' (2007) exploring of the creative tensions of academic life . . . the sport management professoriate has heard their words. But . . . this professoriate has struggled to examine (Frisby, 2005), identify (Chalip, 2006), and explore (Inglis, 2007) . . . (Bruening, Madsen, Evanovich, \& Fuller, 2010, p. 31).

We are still having the same conversation. But the world has changed. Compared with current critical scholarship, discovery, integration, and application are safe terms. No bats being thrown there. What Alvesson and Deetz (2000) would tell us is that we need insight into how our existing knowledge has been shaped, even taken for granted, by our standpoint. We should critique and question our assumptions, and finally transform them. Sulé (2014) would tell those who have been underrepresented and undervalued to enact norms that are aligned with own our positionalities, discard the norms that conflict with those positionalities, and transform norms to bring them into alignment with our positionalities (p. 440).

\section{How to Enact, Discard, Transform}

How many of you have heard Abby Wambach's Barnard College commencement address (Wambach, 2018)? You know, the Wolfpack? She inspired those graduates to consider how things are and how they might be:

Our landscape is overrun with archaic ways of thinking about women, about people of color, about the "other," ... and these ways of thinking are destroying us.

As you go out into the world: Amplify each other's voices. Demand seats for women, people of color and all marginalized people at every table where decisions are made. Call out each other's wins just like we do on the field ... scarcity has been planted inside of us and among us. This scarcity is not our fault. But it is our problem. And it is within our power to create abundance . . . where scarcity used to live.

We are the ones we've been waiting for.

How about Jamele Hill? She was fired from ESPN (Entertainment and Sports Programming Network) for speaking her truth about a norm that conflicted with her positionalities. She now has a new show called Unbothered where she talks about sport at the intersections of race, gender, and politics. She is speaking her mind, owning her truth, and not shying away from it. What about Aly Raisman? Fierce (Raisman, 2017). She spoke her truth, too, and as a result, norms about how our society views women are being transformed. Read the recent New York Times opinion piece by former major leaguer and current MLB broadcaster, Doug Glanville? Ambiguity has always been a friend to racism, he states: “. . . we need to acknowledge racism, and acknowledge that it operates not only with fire hoses and police dogs but also in whispers, in fine print, in invisible ink, in coded language. Until we are fully against it, we are letting it fester, and while we try to sort out the ambiguities, people are suffering" (Glanville, 2019). I am also reminded of Kyle Korver's Player's Tribune piece entitled "Privileged" (Kover, 2019). Many of us, the majority in this room, like Korver, can opt in or opt out. More of the norms benefit us than don't. We don't have to enact, discard, transform. Wambach, Hill, Raisman, Glanville, Korver: they are all telling us we still should. That would have impact. As Wambach said to the women of Barnard, are you picking up what I am laying down here?

We all have bias. Another inconvenient truth, right Lucie (Thibault, 2009)? Most of our bias is unconscious, implicit. And yet, it presents itself in our individual actions and the policies and practices that undergird our organizations. Remember the statistics I shared earlier on the NASSM membership? White people control this institution and most institutions in sport and our society, including the academy, our journals, the Social Science Citation Index. I think you get my point. Our biases are embedded in us as individuals, "regardless of intentions, awareness, or self-image." No one has escaped being shaped by bias and by structures that reinforce bias. In 2017, Robin DiAngelo wrote that "our task is not to exempt ourselves from the impact" (DiAngelo, 2017) of how we have been socialized to the world and this profession, but instead call out - make explicit-how we have been shaped, our taken-forgranted assumptions, and disrupt them. As a sociologist, she 
describes the culture we live in as white supremist. While many associate that concept with extreme and explicit forms of hate, she uses it to describe individual and organizational contexts where Whiteness is the norm, even ideal. DiAngelo stated,

[we] mask white supremacy by rendering invisible-whites, white advantage, and the policies and practices of the institutions we control. This is what we need to make visible, understand, and interrupt . . . naming white supremacy . . . shifts the problem to white people, where it belongs . . . all white people, even white progressives (DiAngelo, 2017).

While I understand where Dr Zeigler, and NASSM in 1987, were coming from in shaping a mission that did not prioritize or protect any individual, group, or university, and I realize what Cuneen and Parks were saying about sport management education as a whole benefitting from NASSM and JSM's focus, I can't help but ask in 2019: if we do not serve the evolving profession as the individuals they are and groups they belong to, then do we run the risk of being exclusionary? If we are not explicit about how sport is a microcosm of society (Lapchick, 2006), then how are we serving the field? Our biases are "hiding in plain sight," right Janet? In Cunningham's (2014) Zeigler address, he appealed to all of us to consider that "justice . . . in sport will only be realized through our collective actions-not our silence" (p. 3). We can all have impact. Mary Hums, the 2009 Zeigler winner, shared with me that behind-thescenes work, advocacy, is needed. It's not all about speaking out. It's not look at me, I did this. It's also the work that is not recognized by the field as impact, but it is. It takes time, energy, thought, and care. It's not, as Mary says, "shiny." But if it weren't for her, the MLB injured list would still be called the disabled list.

So, what can we do? Well, first, "Never say you cannot do something" (Pastore, 2003, p. 10). The time has come for us to try on a different lens, right Donna? And put a plan into action. Be a collegial peer (Pastore, 2003). I have heard some great stories during my preparation for this talk about 2008 Zeigler winner Lucie Thibault's wide circle of colleagues from all over the world. Why? Because she took the time to engage with them at this conference and others. Go to a talk you would not have otherwise attended; I would point to the symposium tomorrow morning ... in case you are looking for a suggestion. Listen, ask a constructive question, make a constructive comment. I heard a story while doing my research for this talk about how Laurence Chalip came to a presentation at a critical time in a younger scholar's career and offered feedback and encouragement. That had impact. Students and professionals new to NASSM, put yourselves out there and introduce yourselves to someone you'd like to talk to, and those of us who've been around a while, be kind. Make time. I know many of us come to the conference partly because it is the one time a year we see some of our friends. I get it. But our membership is telling us that there are in-groups and out-groups. Do something to expand your in-group and disband your out-group this year. Come on. When you meet someone new or listen to a presentation on a new research method or innovative pedagogy, who do you know who might be interested? Connect people to each other, here at the conference or by email later. Do it. When you go home to your campuses, think about how you approach your programs. What is your reward structure for faculty-how does it reinforce the traditional, dominant narrative? How can you enact, discard, transform? (Sulé, 2014).

In his Hall of Fame induction speech, Ryne Sandberg said it's more "than knowing where to find the little red light on the dugout camera" (Sandberg, 2005). Impact is bigger than look at me. Jamele
Hill said, "we are disrupters, the whole function of our job is to hold people . . . accountable" (Hill, 2019). Even ourselves. I have given you examples of big I impact where we can disrupt the structures that work to maintain the status quo, the in-groups, and the out-groups, the metrics and evaluations. And I have given examples of little I impact that have happened, that are happening, and that can happen even more. As our own members have told us, NASSM "should be a diverse and inclusive academic society-one in which all persons can thrive, irrespective of their individual differences" (North American Society for Sport Management, 2016a). Here is the thing, and nothing against NASSS, it is a pretty cool organization and puts on a solid conference, but no one should have to go there in order to feel they and their work are valued. We can do better.

\section{References}

Alvesson, M. (2008). The future of critical management studies. In D. Barry \& H. Hansen (Eds.), The SAGE handbook of new approaches in management and organization (pp. 13-30). London, UK: Sage Publications, Ltd.

Alvesson, M., \& Deetz, S. (2000). Doing critical management research. Thousand Oaks, CA: Sage Publications, Inc.

Armstrong, K.L. (2011). 'Lifting the veils and illuminating the shadows': Furthering the explorations of race and ethnicity in sport management. Journal of Sport Management, 25(2), 95-106. doi:10.1123/ jsm.25.2.95

Boyer, E.L. (1990). Scholarship reconsidered: Priorities of the professoriate. Lawrenceville, NJ: Princeton University Press.

Bruening, J.E., Madsen, R.M., Evanovich, J.M., \& Fuller, R.D. (2010). Discovery, integration, application and teaching: Service learning through sport and physical activity. Sport Management Education Journal, 4(1), 31-48. doi:10.1123/smej.4.1.31

Caproni, P.J., \& Arias, M.E. (1997). Managerial skills training from a critical perspective. Journal of Management Education, 21(3), 292 308. doi:10.1177/105256299702100303

Chalip, L. (2006). Toward a distinctive sport management discipline. Journal of Sport Management, 20(1), 1-21. doi:10.1123/jsm.20.1.1

Cooper, J.N. (2019). Dangerous stereotypes stalk Black college athletes. Retrieved from https://theconversation.com/dangerous-stereotypesstalk-blackcollege-athletes-101655

Cuneen, J., \& Parks, J.B. (1997). Should we serve sport management practice or sport management education? A response to Weese's perspective. Journal of Sport Management, 11(2), 125-132. doi:10. 1123/jsm.11.2.125

Cunningham, G.B. (2014). Interdependence, mutuality, and collective action in sport. Journal of Sport Management, 28(1), 1-7. doi:10. 1123/jsm.2013-0152

DiAngelo, R. (2017). No, I won't stop saying white supremacy. Retrieved from https://www.yesmagazine.org/people-power/no-i-wont-stopsaying-white-supremacy-20170630

Dixon, M.A., \& Bruening, J.E. (2007). Work-family conflict in coaching I: A top-down perspective. Journal of Sport Management, 21(3), 377-406. doi:10.1123/jsm.21.3.377

Doherty, A. (2013). "It takes a village:” Interdisciplinary research for sport management. Journal of Sport Management, 27(1), 1-10. doi:10. $1123 /$ jsm.27.1.1

DuBois, W.E.B. (1903). The souls of black folk. New York, NY: Bantam Classic.

Emmert, M. (2017). Jane Meyer wins \$1.43 M case against Iowa. Retrieved from https://www.desmoinesregister.com/story/sports/ college/iowa/hawkcentral/2017/05/04/janemeyer-wins-1-43-m-caseagainst-iowa/310303001/ 
Fink, J.S. (2008). Gender and sex diversity in sport organizations: Concluding comments. Sex Roles, 58(1-2), 146-147. doi:10.1007/ s11199-007-9364-4

Fink, J.S. (2016). Hiding in plain sight: The embedded nature of sexism in sport. Journal of Sport Management, 30(1), 1-7. doi:10.1123/jsm. 2015-0278

Frisby, W. (2005). The good, the bad, and the ugly: Critical sport management research. Journal of Sport Management, 19(1), 1-12. doi:10.1123/jsm.19.1.1

Geraci, L., Balsis, S., \& Busch, A.J.B. (2015). Gender and the h index in psychology. Scientometrics, 105(3), 2023-2034. doi:10.1007/ s11192-015-1757-5

Glanville, D. (2019). I was racially taunted on television. Wasn't I? Retrieved from https://www.nytimes.com/2019/05/18/opinion/sunday/ doug-glanville-cubs.html?smtyp=cur\&smid=tw-nytimes

Haley, U.C.V., Page, M.C., Pitsis, T.S., Rivas, J.L., \& Yu, K.F. (2017). Measuring and achieving scholarly impact: A report from the Academy of Management's Practice Theme Committee. Available at http://aom.!org/uploadedFiles/About_AOM/StrategicPlan/AOM ScholarlyImpactReport.pdf.

Harding, S.G. (1986). The science question in feminism. Ithaca, NY: Cornell University Press.

Hill, J. (2019). Jamele Hill a disrupter. Retrieved from https://dailycampus. com/stories/2019/3/7/jemele-hill-a-disrupter

Holosko, M.J., Barner, J.R., \& Allen, J.L. (2016). Citation impact of women in social work: Exploring gender and research culture. Research on Social Work Practice, 26(6), 723-729. doi:10.1177/ 1049731515598374

Howard, D.R. (1999). The changing fanscape for big-league sports: Implications for sport managers. Journal of Sport Management, 13, 78-91. doi:10.1123/jsm.13.1.78

Husky Sport. Retrieved from https://www.huskysport.uconn.edu

Inglis, S. (2007). Creative tensions and conversations in the academy. Journal of Sport Management, 21(1), 1-14. doi:10.1123/jsm.21.1.1

Kover, K. (2019). Privileged. Retrieved from https://www.theplay erstribune.com/en-us/articles/kyle-korver-utah-jazz-nba

Kram, K.E. (1988). Mentoring at work: Developmental relationships in organizational life. Lanham, MD: University Press of America.

Lapchick, R.E. (2006). New game plan for college sport. ACE/Praeger Series on Higher Education. Santa Barbara, CA: Praeger.

Mahony, D.F. (2008). No one can whistle a symphony: Working together for sport management's future. Journal of Sport Management, 22(1), 1-10. doi:10.1123/jsm.22.1.1

Meyerson, D.E., \& Kolb, D.M. (2000). Moving out of the arm chair: Developing a framework to bridge the gap between feminist theory and practice. Organization, 7(4), 553-571. doi:10.1177/135050840074003

Mintzberg, H. (1982). If you're not serving Bill and Barbara, then you're not serving leadership. In J.G. Hunt, U. Sekaran, \& C.A. Schriesheim (Eds.), Leadership beyond establishment views (pp. 239-259). Carbondale, IL: Southern Illinois University Press.

National Basketball Association. (2019). Inclusive culture. Retrieved from https://inclusion.nba.com/inclusive-culture/

National Collegiate Athletic Association. (2009). Retrieved from https:// www.ncaa.org/sites/default/files/DiversityInAthletics2009.pdf

National Science Foundation. (2019). Retrieved from https://www.nsf. gov/od/oia/publications/Broader_Impacts.pdf

Neuman, W.L. (2003). Social research methods: Qualitative and quantitative approaches. New York, NY: Allyn and Bacon.

North American Society for Sport Management. (2016a). 2016-2021 Strategic Plan. Author. Retrieved from https://www.nassm.org/ sites/default/files/NASSM\%20Strategic\%20Plan\%202016-2021.pdf
North American Society for Sport Management. (2016b). Climate survey: Summary of findings. Author.

North American Society for Sport Management. (2018). NASSM Report Goal 7: Understand and serve the perspectives of under-represented and underserved stakeholders. Author.

North American Society for Sport Management. (2019). Membership demographics. Author.

Parks, J.E. (1992). Scholarship: The bitter "bottom line" in, sport management. Journal of Sport Management, 6, 220-229. doi:10.1123/ jsm.6.3.220

Pastore, D.L. (2003). A different lens to view mentoring in sport management. Journal of Sport Management, 17(1), 1-12. doi:10.1123/jsm. 17.1.1

Raisman, A. (2017). Fierce: How competing for myself changed everything. New York, NY: Little, Brown, \& Company.

Rhimes, S. (2015). Year of yes: How to dance it out, stand in the sun and be your own person. New York, NY: Simon and Schuster.

Sandberg, R.D. (2005). Retrieved from https://americanrhetoric.com/ speeches/rynesandbergbaseballhalloffame.htm

Schulenkorf, N., Sherry, E., \& Rowe, K. (2016). Sport for development: An integrated literature review. Journal of Sport Management, 30(1), 22-39. doi:10.1123/jsm.2014-0263

Shaw, S., \& Frisby, W. (2006). Can gender equity be more equitable? Promoting an alternative frame for sport management research, education, and practice. Journal of Sport Management, 20(4), 483-509. doi:10.1123/jsm.20.4.483

Shaw, S., \& Hoeber, L. (2003). "A strong man is direct and a direct woman is a bitch": Gendered discourses and their influence on employment roles in sport organizations. Journal of Sport Management, 17(4), 347-375. doi:10.1123/jsm.17.4.347

Shaw, S., Wolfe, R., \& Frisby, W. (2011). A critical management studies approach to sport management education: Insights, challenges and opportunities. Sport Management Education Journal, 5(1), 1-13. doi:10.1123/smej.5.1.1

Shilbury, D. (2012). Competition: The heart and soul of sport management. Journal of Sport Management, 26(1), 1-10. doi:10.1123/jsm.26.1.1

Spaaij, R., Oxford, S., \& Jeanes, R. (2016). Transforming communities through sport? Critical pedagogy and sport for development. Sport, Education and Society, 21(4), 570-587. doi:10.1080/13573322. 2015.1082127

Sulé, V.T. (2014). Enact, discard, and transform: A critical race feminist perspective on professional socialization among tenured Black female faculty. International Journal of Qualitative Studies in Education, 27(4), 432-453. doi:10.1080/09518398.2013.780315

Svensson, P.G., \& Levine, J. (2017). Rethinking sport for development and peace: The capability approach. Sport in Society, 20(7), 905-923. doi:10.1080/17430437.2016.1269083

Taylor, E.A., Smith, A.B., Welch, N.M., \& Hardin, R. (2018). "You should be flattered!": Female sport management faculty experiences of sexual harassment and sexism. Women in Sport and Physical Activity Journal, 26(1), 43-53. doi:10.1123/wspaj.2017-0038

Thibault, L. (2009). Globalization of sport: An inconvenient truth. Journal of Sport Management, 23(1), 1-20. doi:10.1123/jsm.23.1.1

Wambach, A. (2018). Make failure your fuel. Retrieved from https:// time.com/5281711/abby-wambach-barnard-commencement-2018speech/

Weese, W.J. (1995). If we're not serving practitioners, then we're not serving sport management. Journal of Sport Management, 9(3), 237243. doi:10.1123/jsm.9.3.237

Zeigler, E. (1987). Sport management: Past, present, future. Journal of Sport Management, 1(1), 4-24. doi:10.1123/jsm.1.1.4 